\title{
Accuracy assessment of the quiet-time ionospheric F2 peak parameters as derived from COSMIC-2 multi-GNSS radio occultation measurements
}

\author{
Iurii Cherniak $^{1, *}$, Irina Zakharenkova ${ }^{1}$, John Braun ${ }^{1}$, Qian $\mathrm{Wu}^{1,2}$, Nicholas Pedatella ${ }^{1,2}$, \\ William Schreiner ${ }^{1}$, Jan-Peter Weiss ${ }^{1}$, and Douglas Hunt ${ }^{1}$ \\ ${ }^{1}$ COSMIC Program Office, University Corporation for Atmospheric Research, Boulder, CO 80301, USA \\ ${ }^{2}$ High Altitude Observatory, National Center for Atmospheric Research, Boulder, CO 80301, USA
}

Received 30 June 2020 / Accepted 24 December 2020

\begin{abstract}
The Constellation Observing System for Meteorology, Ionosphere, and Climate 2 (COSMIC-2) mission was launched into a low-inclination $\left(24^{\circ}\right)$ orbit on June 25, 2019. Six satellites, each with an advanced Tri-GNSS Radio-Occultation Receiver System (TGRS), provide a global and uniform data coverage of the equatorial region with several thousand electron density profiles daily. The COSMIC-2 electron density profiles, and specifically the derived ionospheric F2 peak parameters, are properly validated in this study with reliable "truth" observations. For this purpose, we used manually scaled ionograms from 29 ground-based ionosondes located globally at low and middle latitudes. For this validation campaign, we considered only geomagnetically quiet conditions in order to establish benchmark level of the new mission's ionospheric observation quality and to evaluate the operational capability of the COSMIC-2 Radio Occultation (RO) payload at the background of normal day-to-day variability of the ionosphere. For reliable colocations between two independent techniques, we selected only COSMIC-2 RO profiles whose F2 peak point coordinates were within $5^{\circ}$ of the closest ionosonde. Our comparison of the ionospheric F2 peak height (hmF2) derived from COSMIC-2 RO and ground-based ionosonde measurements showed a very good agreement, with a mean of $\sim 5$ and $\sim 2 \mathrm{~km}$ at low and middle latitudes, respectively, while RMS error was of $\sim 23$ and $\sim 14 \mathrm{~km}$, respectively. That range corresponds to a deviation of only 6-9\% from the reference, ionosonde observations. Examination of representative collocation events with multiple (2-5) simultaneous RO tracks near the same ionosonde with different RO geometry, multisatellite and multi-GNSS combination give us observational evidence that COSMIC-2 RO-based EDPs derived from GPS and GLONAS links show good self-consistency in terms of the ionospheric F2 peak values and electron density profile shape. We can conclude that COSMIC-2 provides high quality data for specification the ionospheric electron density at the F2 peak region.
\end{abstract}

Keywords: COSMIC-2 / GNSS / radio occultation / ionosphere / electron density profile / F2 peak / ionosondes

\section{Introduction}

The Global Positioning System Meteorology (GPS/MET) Experiment, which placed a GPS receiver onboard a LowEarth-Orbiting (LEO) satellite in 1995, was a pioneer in demonstrating the applicability of the GPS-based Radio Occultation (RO) technique to retrieve a vertical distribution of electron density in the Earth's ionosphere (Hajj \& Romans, 1998; Schreiner et al., 1999). The first generation of the Constellation Observing System for Meteorology, Ionosphere, and Climate (COSMIC) also had great success as the first multi-satellite

\footnotetext{
*Corresponding author: iurii@ucar. edu
}

RO-based mission for probing the Earth's ionosphere with unprecedentedly dense coverage on a global scale. The COSMIC-1 mission, consisting of six identical satellites was launched on April 15, 2006. The orbit inclination was $72^{\circ}$ and the orbit altitude was 700-800 km above the Earth's surface. Depending on the constellation state, COSMIC-1 provided 1500-2500 RO soundings of the ionosphere and atmosphere per day. During 2006-2020, the mission provided 4.6 million ionospheric electron density profiles (EDPs). Officially, the COSMIC-1 mission was decommissioned April 30, 2020.

Fortunately, the second generation of COSMIC - the COSMIC-2 mission - was launched on June 25, 2019. The six COSMIC-2 satellites were placed into a low-inclination orbit 
$\left(24^{\circ}\right)$ with $\sim 700 \mathrm{~km}$ initial orbit altitude. The main payload instrument of the COSMIC-2 mission is the Tri-GNSS (Global Navigation Satellite System) Radio Occultation System instrument (TGRS) for RO probing of the atmosphere and ionosphere, developed by the NASA Jet Propulsion Laboratory, based on COSMIC-1 heritage (Tien et al., 2012; Schreiner et al., 2020). This receiver tracks not only GPS but also navigation signals from the Russian GLONASS (In Russian: GLObalnaya NAvigazionnaya Sputnikovaya Sistema) system that substantially increases the number of ionospheric and atmospheric RO retrievals.

To date, the COSMIC-2 is the largest equatorial constellation of six full-size satellites to study the equatorial ionosphere, and it can provide unprecedentedly dense coverage of RO observations - up to 5000 EDPs per day for operational constellation. Even now at the beginning stage of the mission, COSMIC-2 provides 2000 ionospheric EDPs per day, which is comparable to the COSMIC-1 ionospheric occultation number with all six satellites operating. Due to the orbit inclination, the COSMIC-2 RO events occur mainly within $\pm 30^{\circ}$ geographic latitudes (GLAT) with excellent coverage of low and equatorial latitudes at all longitudes. The equatorial ionosphere is a puzzling region with a strong quiet-time day-to-day variability, the largest values of plasma density and electron content, the steepest ionospheric gradients, and also the phenomenon of equatorial plasma bubbles. The advanced COSMIC-2 instruments measure high-rate amplitude and phase scintillations both above and below the satellite orbit, which allows detection and monitoring of ionospheric plasma density structures of various scales. The synergy of new data and plasma density observations of the equatorial ionosphere is required to better understand the physical processes in this region, improvements of model simulations, and forecasting. In coming years with normal operational configuration of all spacecrafts, COSMIC-2 will be an important data provider for equatorial ionospheric research.

Prior to conducting scientific application studies, the most important activity for each new mission is data quality validation and assessment of the instrument's performance. The quality of COSMIC-1 ionospheric observations was evaluated by different research teams with direct and statistical comparisons provided by the major benchmark instruments ground-based stations of vertical sounding of the ionosphere (ionosondes) and incoherent scatter radars. In particular, Lei et al. (2007) made an assessment of the preliminary COSMIC-1 RO observations by comparing COSMIC-1 EDPs with measurements provided by Millstone Hill and Jicamarca incoherent scatter radars and 31 ionosondes. Krankowski et al. (2011) evaluated the COSMIC-1 RO ionospheric EDPs with a network of 7 ionosondes in Europe and found a very good agreement with ionosonde profiles both in the ionospheric F2 layer peak electron density $(\mathrm{NmF} 2)$ and the bottom side part of the electron density $(\mathrm{Ne})$ profiles. Habarulema et al. (2014) compared the COSMIC-1 ionospheric F2 peak parameters with 4 Digisondes located in the Africa-Atlantic sector. Cherniak \& Zakharenkova (2014) investigated similarities and differences in the F2 peak parameters and shape of the COSMIC-1 RO EDPs compared to mid-latitude incoherent scatter radar soundings. The F2 region profiles derived from the COSMIC-1 RO were also found to be reasonably accurate in comparison with Arecibo incoherent scatter radar measurements (Kelley et al.,
2009). Results of these studies confirm good performance of RO ionospheric observations and great potential for ionospheric and Space Weather applications. Having been proven a valuable data source for ionosphere plasma density estimates on a global scale, the COSMIC-1 mission has contributed to a large number of research activities for ionospheric climatology and weather during the past 15 years. For example, global climatology of the sporadic E layer (Arras et al., 2008), the Weddell Sea Anomaly (e.g., He et al., 2009; Zakharenkova et al., 2017), main ionospheric trough (e.g., Lee et al., 2011), estimation of plasmaspheric electron content (e.g., Pedatella \& Larson, 2010; Pedatella et al., 2011; Cherniak et al., 2012; Klimenko et al., 2015), evaluation of empirical ionospheric models (e.g., Yue et al., 2013; Cherniak \& Zakharenkova, 2019; Kashcheyev \& Nava, 2019) and assimilative ionospheric models (e.g., Komjathy et al., 2010; Dymond et al., 2017).

The objective of the present paper is to evaluate the accuracy of the ionospheric F2 peak parameters retrieved from RO EDPs from the new COSMIC-2 multi-satellite mission by direct and statistical comparison with globally distributed ionosonde observations. For geomagnetically quiet periods of low solar activity (January-February 2020), we analyzed results of collocated RO-ionosonde measurements in order to assess the ionospheric F2 peak parameters. For the analysis, we considered only geomagnetically quiet conditions - a minimum Dst index should be above $-25 \mathrm{nT}$ and the daily sum of eight 3-h $K p$ index values was less than or equal to 20 . The accuracy assessment of the ionospheric F2 peak parameters of COSMIC-2 RO measurements for such very quiet conditions allows us to establish benchmark level of the new mission's ionospheric observation quality and to evaluate the operational capability of the RO payload at the background of normal day-to-day variability of the ionosphere. Knowledge on the expected behavior in the non-disturbed conditions allows to estimate more precisely ionospheric responses to the different types of Space Weather activity against the quiet-time ionosphere peak parameters.

\section{Database}

We used the Level 2 data product provided by COSMIC Data Analysis and Archive Center (CDAAC) - "ionPrf" files of ionospheric electron density profiles. CDAAC COSMIC-2 products are available via https://doi.org/10.5065/t353-c093. Each "ionPrf" file contains information about altitude, latitude, and longitude of RO tangent point and corresponding electron density $(\mathrm{Ne})$ value. The CDAAC routinely generates ionospheric EDP products using the Abel inversion technique from the total electron content (TEC) observations along the receivertransmitter link. In the ionospheric RO context, the Abel inversion technique is applied to the slant TEC (sTEC) data observed by a GNSS receiver onboard LEO satellites in order to obtain the electron density expressed as a function of height. Under the assumption of straight-line propagation of GNSS signals in the ionosphere, the difference between the L1 and L2 phase path measurements is approximately proportional to the TEC along the line from the LEO satellite to the GNSS satellite. In the standard Abel RO inversion, the ionospheric electron density is assumed constant due to the local spherical symmetry 
assumption in each spherical layer during each occultation observation. Each sTEC observation defines a layer in the vertical profile, therefore, the sampling rate at which the LEO gathers GNSS data will determine the vertical resolution of the profile (for instance, one sampling each second $(1 \mathrm{~Hz})$ yields to a vertical resolution of units of $\mathrm{km}$ ). Starting with the uppermost observation and processing downwards assuming spherical symmetry, the electron density profile can be obtained. Under this assumption (i.e., assuming only vertical electron density gradients) and straight-line propagation, the calibrated TEC is related to electron density, $N e$, as a function of the radius from the Earth's center. The retrieval technique of ionospheric electron density from RO TEC measurements using the Abel inversion method is described in more detail by Syndergaard et al. (2006) and Tsai et al. (2001). Accuracy and limitations of the Abel inversion technique for COSMIC-1 EDPs retrievals are further discussed by Yue et al. (2010) and Pedatella et al. (2015).

For all previous RO missions, the accuracy of the Abel inverted GPS RO electron density profiles has been established through extensive comparisons with independent observations. Owing to the large number of available ionosonde observations along with their reliable determination of the F2 layer peak parameters, GPS RO electron density profiles have been mainly validated through comparison with ionosonde observations of the F2 peak density ( $\mathrm{NmF} 2$ ) and peak height (hmF2). With the spherical symmetry assumption, it is expected that the discrepancies with respect to the ionosonde measurements of foF 2 are comprised from $10 \%$ to $20 \%$ (which corresponds to discrepancies of $20-40 \%$ respectively in electron density NmF2, see (Schreiner et al., 1999).

We note that all preceding RO-based missions including COSMIC-1 were able to track signals from GPS only. An important advantage of the COSMIC-2 mission is its ability to track navigation signals from two GNSS systems - GPS and GLONASS - that has led to an increased number of ionospheric and atmospheric RO retrievals. Apart from the EDP product, COSMIC-2 also provides line-of-sight TEC observations (both above the satellite orbit and in occultation) to support ionosphere/space weather operations and research.

Being one of the pioneering instruments for investigation of the Earth's ionosphere, vertical ionospheric sounding stations (ionosondes) are still the "benchmark" data source for unbiased measurements of electron density in the bottomside ionosphere and in the ionospheric F2 peak layer. Globally distributed ionosonde stations provide the reference dataset for validation and accuracy estimation of GNSS RO ionospheric retrievals. In this study, we used measurements provided by 29 ionosondes, whose locations are shown in Figure 1a. Coordinates of the selected ionosondes are listed in Table 1 . The majority of these ground-based stations are equipped with DPS (DigisondePortable-Sounder) Digisondes (Reinisch et al., 2009), while the remaining stations have VIPIR2 (Vertical Incidence Pulsed Ionospheric Radar, Version 2) ionosondes (in Japan) and IPS ionosondes (in the Australian region). Figure 1b presents an example of daily COSMIC-2 RO EDP coverage. The blue dots show the location of the F2 peak point extracted from each EDP. Due to its low orbit inclination, COSMIC-2 provides an excellent, dense coverage of equatorial and low latitudes within $\pm 30^{\circ}$ GLAT, a region mostly covered by oceans.
For many decades, ionosondes of different types provide an accurate "ground truth" knowledge of the bottomside vertical EDP at the ionosonde location (e.g. Reinisch \& Galkin, 2011). In this study, benchmark reference instrument database was extracted from three different types of modern ionospheric sounders. But they all are based on the same physical principle for $\mathrm{Ne}$ estimation (reflection on plasma frequency) and technology - pulsed radar in the HF band for determining reflection layer virtual height when the time delay of the echo is measured. The electron density $\mathrm{Ne}$ is measured directly $(\mathrm{NmF} 2=(1 / 80.6)$. $\left.(\mathrm{foF} 2)^{2}\right)$, and the height of the layer is obtained throughout the true height inversion procedure. The digital sounding systems were developed to obtain higher quality ionograms. In particular, DPS4D ionosonde specification indicates the nominal resolution of $2.5 \mathrm{~km}$ in height and $50 \mathrm{kHz}$ in transmitted/received frequency (DPS4D Specification, 2020).

The expert scaling of digital ionograms allows to get the accurate F2 peak parameters which can serve as the "truth" reference for RO observations analysis. The recent study by Dandenault et al. (2020) reports that even for historical ionograms obtained in the pre-digital era, the expert-mode scaling gives typically better than $5 \%$ uncertainty for benign ionograms. The biggest uncertainties in ionosonde EDP retrievals appear for the F2 layer peak height due to ionogram inversion procedure in order to obtain the real altitude of reflection on particular frequency. Chen et al. (1994) compared co-located incoherent scatter radar and Digisonde measurements and reported that average height differences for Digisonde-derived peak heights are between $-4 \mathrm{~km}$ in winter and -14 to $17 \mathrm{~km}$ in springsummer seasons and spring-summer uncertainties can be reduced to $7-10 \mathrm{~km}$ by accounting more precisely the E-F valley. The ionosonde-derived ordinary wave critical frequency represents an unbiased measurements of electron density. The reading accuracy of critical frequency of the F2 peak layer (foF2) for cases of manually-scaled digital ionograms is nominally $0.1 \mathrm{MHz}$ (e.g. Piggott \& Rawer, 1978).

It is important to note that RO-based EDPs should not be interpreted as classical vertical profiles. The geographical projections of the RO tangent points at the top and at the bottom of a profile may be separated by several thousand kilometers. So, the geometry of ground-based ionosonde sounding and space-based RO measurements is completely different, and this comparison suffers from representativeness differences. In previous RO validation studies, the collocation definition window (RO EDP location vs. ionosonde/ISR location) varied broadly from $2^{\circ}$ (e.g., Lei et al., 2007) to $4^{\circ}-6^{\circ}$ (e.g., Lei et al., 2007; Sadighi et al., 2009; Habarulema et al., 2014) and up to $10^{\circ}-19^{\circ}(\sim 1000-2000 \mathrm{~km})$ (e.g., Schreiner et al., 1999; Jakowski et al., 2002; Garcia-Fernandez et al., 2005; Kelley et al., 2009; Krankowski et al., 2011).

To determine a colocation criterion for RO vs. ionosonde measurements, we analyze the spatial correlation factor of the ionospheric plasma density variability. For the quiet-time midlatitude ionosphere, the correlation distance (correlation coefficient $r>0.70$ ) can be considered as approximately $1500-3000 \mathrm{~km}$ in an east-west direction and 1000-1800 km in a north-south direction (Rush \& Edwards, 1976; Klobuchar $\&$ Kunches, 2000). For equatorial and low latitudes, this correlation distance is smaller due to much larger temporal and spatial variability of the equatorial ionosphere and it can be 

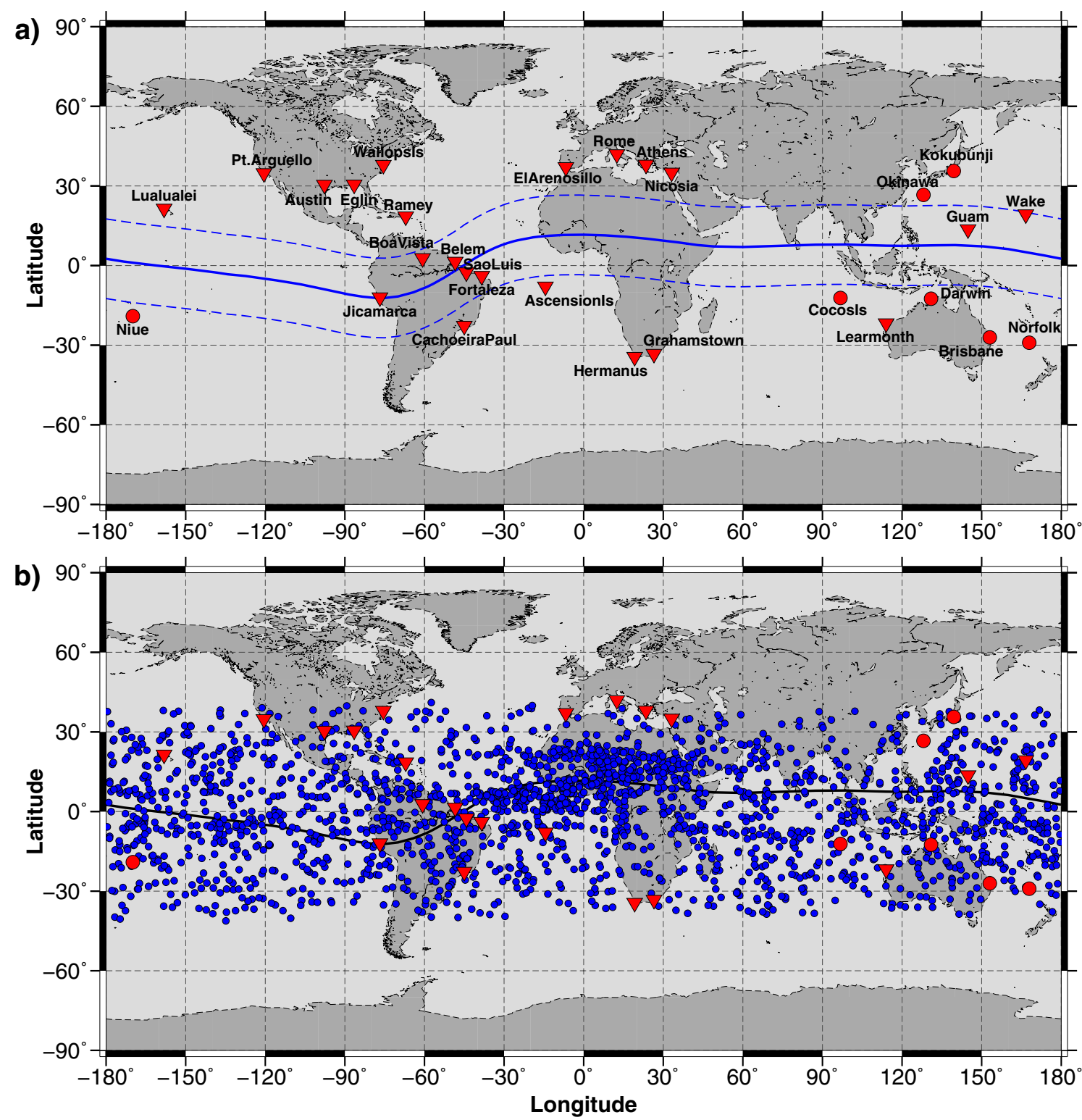

Fig. 1. (a) Geographical map with Digisondes (red triangle) and ionosondes (red circles) locations used in this study; lines show the magnetic equator and $\pm 15^{\circ}$ MLAT. (b) Example of global distribution of the F2 peak points as derived from COSMIC-2 RO observations during 24 hr (25 January 2020).

considered as 1000-1500 $\mathrm{km}$ in an east-west direction and $500-1000 \mathrm{~km}$ in a north-south direction (Klobuchar \& Kunches, 2000). Since our primary goal is evaluation of the F2 peak parameters derived from COSMIC-2 RO, we selected the maximal distance of $5^{\circ}(\sim 500 \mathrm{~km})$ as the criterion for a reliable colocation between the two independent techniques for any selected COSMIC-2 RO EDP, the tangent point coordinates of the $\mathrm{F} 2$ peak point should be within a $5^{\circ}$ radius of the ionosonde location and a clear ionosonde's ionogram should be available within $\pm 15 \mathrm{~min}$ interval of the collocation time. We should note that ionograms (spread-F conditions) and RO profiles affected by ionospheric irregularities associated with equatorial plasma bubbles have been excluded from the analysis.
As we considered only quiet-time geomagnetic condition for our validation study, there was no registration of storm-induced LSTIDs propagated through the mid/low latitude ionosphere and capable of adversely impacting both the ground truth ionosonde observations and RO EDPs. Magnitude of any quiet-time MSTIDs should be significantly smaller than storm-induced LSTIDs (e.g., 0.1-0.5 TECU vs. 1-3 TECU in ground-based GNSS observations). It is difficult to resolve it using a single instrument location, and only bistatic and multi-site technique (e.g., recent Net-TIDE project) allows to reliably detect and estimate MSTIDs propagation parameters in Digisonde data (e.g. Reinisch et al., 2018; Altadill et al., 2020). So, for our study, we consider as negligible any impact of MSTIDs propagation on accuracy of the F2 peak 
parameters derived from vertical sounding ionograms and on the RO-ionosonde cross-comparison results as well.

From these selected (and available) ionosondes, a major portion is represented now by DPS-4D Digisondes - ionograms are scaled in automatic mode in real time using the ARTIST (Automated Real Time Ionogram Scaler with True height) software and sent to the DIDBase (Digital Ionogram Data Base) repository. These low latency observations are extremely valuable for operational monitoring of ionospheric conditions and near real-time assimilative models of the ionosphere. But for validation tasks and precise accuracy assessment, we chose not to use auto-scaled ionospheric F2 peak parameters since auto-scaling errors can bring additional uncertainties and biases and lead to shifted statistical characteristics especially for equatorial ionosphere conditions. Traditionally to get the most accurate results, ionograms should be checked and processed manually in the "expert mode". This is a very time-consuming and laborintensive process; thus, only $\sim 7 \%$ of available ionograms in DIDBase underwent this process of manually validating the autoscaling results. Validation goals of the present study demanded accurate information of EDPs for collocation analysis - so, all the ionogram records considered were manually scaled in the expert mode. The key parameters are parameters of the peak of the ionospheric F2 layer, namely, the highest electron density concentration in the ionosphere. Directly from ionograms and analysis of the ordinary-mode echoes, one can scale critical frequency of the F2 peak (foF2) and virtual heights $\left(h^{\prime} \mathrm{E}, \mathrm{h}^{\prime} \mathrm{F} 1, \mathrm{~h}^{\prime} \mathrm{F} 2\right)$. The critical frequency of the F2 layer, which is the highest o-ray frequency of the $\mathrm{F} 2$ layer reflection, is related directly with electron density at the F2 peak (NmF2) since NmF2 $\left(\mathrm{el} / \mathrm{cm}^{3}\right)=1.24 \times 10^{4} \cdot(\mathrm{foF} 2[\mathrm{MHz}])^{2}$. The true F2 peak height (hmF2) and true height vertical EDP $N e(h)$ can be obtained from the true height inversion analysis using special software, e.g. ARTIST, or the expert ionogram interpretation tool SAO Explorer (Reinisch \& Galkin, 2011), etc. Ionograms are recorded typically every 5-15 min. So, for all considered colocation events, a sequence of ionograms were scaled manually to retrieve the main parameters foF $2, \mathrm{NmF} 2$, and $\mathrm{hmF} 2$, as well as an electron density profile $\mathrm{Ne}(h)$. Importantly, ionosondes can provide only the bottomside part of EDP up to the F2 peak, the topside part of profile is the result of fitting a model to the measured peak electron density value. By the ARTIST software, the electron density profile above the F2 layer peak is approximated by an $\alpha$-Chapman function with a constant scale height that is derived from the bottomside profile shape near the F2 peak (Reinisch \& Huang, 2001). This approximation does not provide a realistic distribution of the density in the topside ionosphere (e.g. Belehaki et al., 2003). That is why the present study focused on the F2 peak parameters and the bottomside part of EDPs only. For many cases when ionograms or the sequence of nearest ionograms within \pm 15 min were affected by strong spread $\mathrm{F}$ or blanketing sporadic $\mathrm{E}$, these colocation events were removed from the analysis.

\section{Results and discussion}

\subsection{Multiple collocations of COSMIC-2 EDPs}

Quite rarely for the COSMIC-1 mission, multiple occultation traces happened to occur in the vicinity of a single ionosonde at
Table 1. List of selected ground-based ionosondes.

\begin{tabular}{|c|c|c|c|}
\hline & $\begin{array}{l}\text { Geographic } \\
\text { latitude }\end{array}$ & $\begin{array}{l}\text { Geographic } \\
\text { longitude }\end{array}$ & $\begin{array}{c}\text { Geomagnetic } \\
\text { latitude }\end{array}$ \\
\hline \multicolumn{4}{|l|}{ American sector } \\
\hline Pt. Arguello & 34.8 & 239.5 & 42.3 \\
\hline Austin & 30.4 & 262.3 & 39.7 \\
\hline Eglin & 30.5 & 273.5 & 41.1 \\
\hline Wallops Island & 37.9 & 284.5 & 49.2 \\
\hline Ramey & 18.5 & 292.9 & 29.8 \\
\hline Boa Vista & 2.8 & 299.3 & 11.4 \\
\hline Belem & 1.4 & 311.6 & 6.9 \\
\hline Sao Luis & -2.6 & 315.8 & 6.9 \\
\hline Fortaleza & -3.9 & 321.6 & 5.9 \\
\hline Jicamarca & -12.0 & 283.2 & 0.7 \\
\hline Cachoeira & -22.7 & 315.0 & -13.6 \\
\hline \multicolumn{4}{|c|}{ Paulista } \\
\hline \multicolumn{4}{|c|}{ Europe-African sector } \\
\hline Rome & 41.9 & 12.5 & 42.3 \\
\hline Athens & 38.0 & 23.5 & 36.4 \\
\hline El Arenosillo & 37.1 & 353.3 & 41.4 \\
\hline Nicosia & 35.0 & 33.2 & 31.7 \\
\hline Ascension & -7.9 & 345.6 & -6.6 \\
\hline \multicolumn{4}{|l|}{ Island } \\
\hline Grahamstown & -33.3 & 26.5 & -33.9 \\
\hline Hermanus & -34.4 & 19.2 & -33.6 \\
\hline \multicolumn{4}{|c|}{ Asian-Pacific sector } \\
\hline Kokubunji & 35.7 & 139.5 & 25.7 \\
\hline Okinawa & 26.7 & 128.2 & 15.5 \\
\hline Wake & 19.3 & 166.7 & 13.7 \\
\hline Guam & 13.6 & 144.9 & 4.2 \\
\hline Cocos Island & -12.2 & 96.8 & -23.2 \\
\hline Darwin & -12.5 & 130.9 & -22.9 \\
\hline Learmonth & -21.8 & 114.0 & -33.0 \\
\hline Brisbane & -27.1 & 153.1 & -35.4 \\
\hline Norfolk & -29.0 & 168.0 & -34.5 \\
\hline Niue & -19.1 & 190.1 & -21.2 \\
\hline Lualualei & 21.4 & 201.8 & 20.0 \\
\hline
\end{tabular}

the same time. For the COSMIC-2 mission with a multi-GNSS receiver, a number of multiple collocations of EDPs in the close proximity from each other increases. This allows us to examine the quality and self-consistency of COSMIC-2 EDPs as derived from simultaneous tracking of different navigation system signals and from different COSMIC-2 satellites. Figure 2 shows representative examples of multiple collocated $\mathrm{RO}$ events in the direct proximity of various ionosondes. For all cases, the selected RO EDPs had the F2 peak point within $5^{\circ}$ distance of an ionosonde.

First, we compared simultaneous RO events for GPS and GLONASS links to analyze if there are any principal differences in RO-based EDPs retrieved using different navigation system signals. Figure $2 \mathrm{a}$, left plot, illustrates a case when two COSMIC-2 spacecraft (E3 and E5) performed two RO events with similar RO traces close to the Hermanus ionosonde located in South Africa. The TGRS receiver onboard spacecraft E3 tracked navigation signals from GPS satellite PRN11, whereas spacecraft E5 tracked signals from GLONASS satellite R22. Figure 2a, right plot, shows a comparison of RO-derived EDPs and the reference from the Hermanus ionosonde. Resulted RO EDPs (blue and black lines) show (1) a high degree of 
a) Hermanus (-34.4; 19.22) 3 Feb 2020
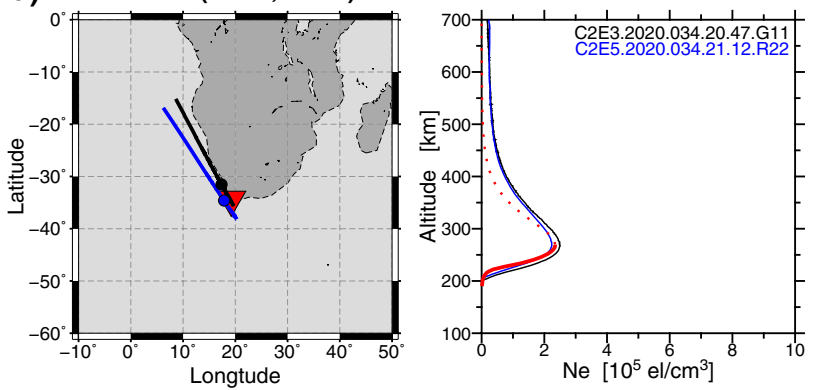

b) Ramey (18.5; -67.1) 6 Feb 2020
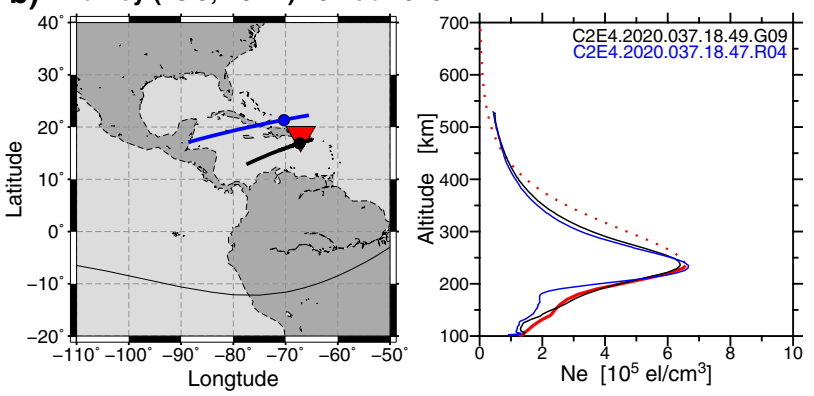

c) Lualualei $(21.43 ;-158.15) 3$ Feb 2020
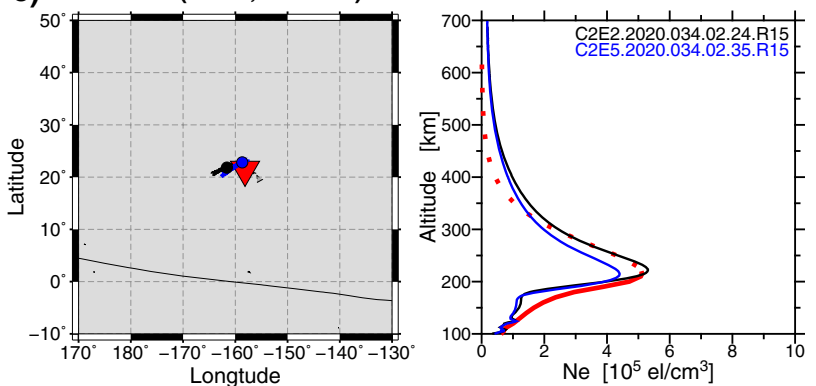

d) Athens (38.0; 23.5) 6 Feb 2020

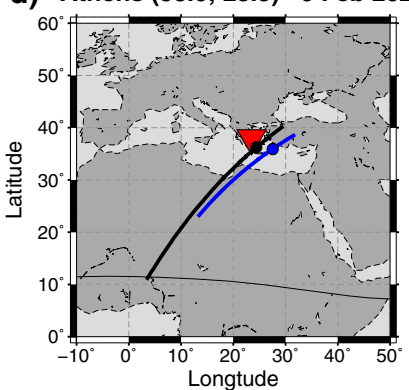

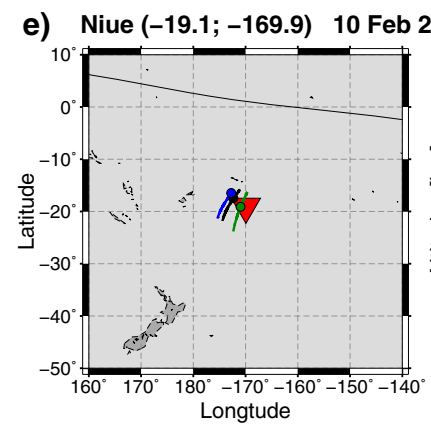

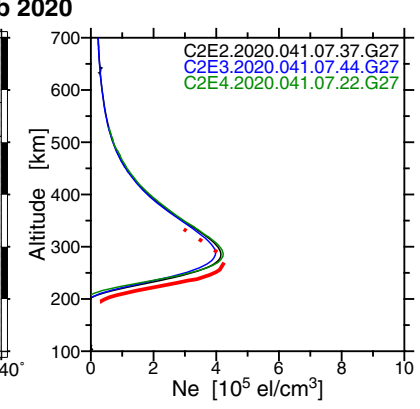

f) Cachoeira Paulista (-22.7; -45.0) 24 Jan 2020
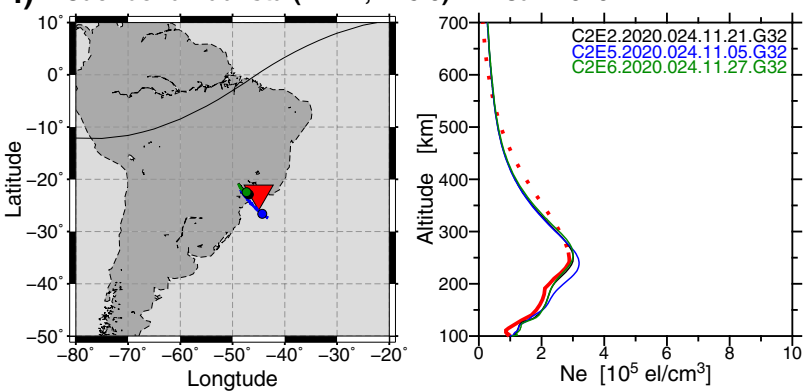

g) Darwin $(-12.5 ; 130.9) 2$ Feb 2020

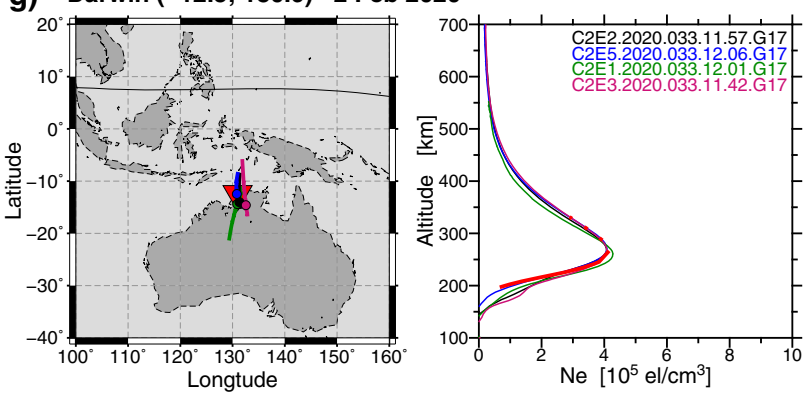

h) Sao Luis (-2.6; -44.2) 9 Feb 2020

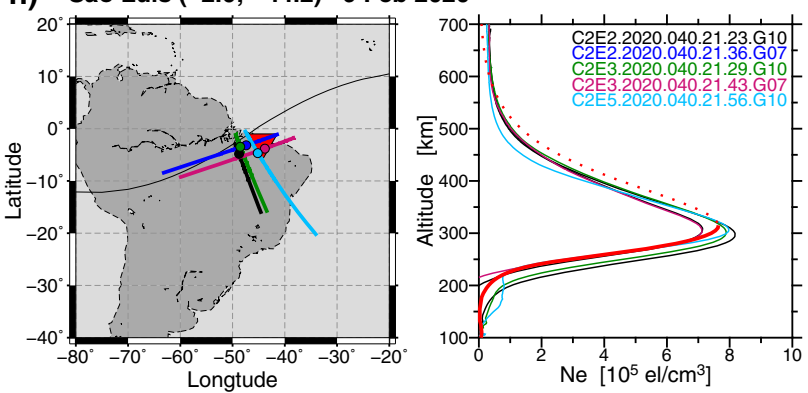

Fig. 2. (a-h) Examples of multiple COSMIC-2 RO electron density profiles as compared with collocated ionosondes. For each panel, left plot shows a geographical map with the ionosonde location (red triangle) and RO tangent points projection (small dots show the F2 peak point location on the trace), black line depicts the magnetic equator; right plot shows RO-derived $\mathrm{Ne}$ profiles and ionosonde-derived $\mathrm{Ne}$ profile (solid red line for the measured bottomside part and red dots for modeled topside part of Ne profile). File names like "C2E3.2020.034.20.47.G11" mean COSMIC-2 mission, spacecraft E3, year 2020, day of year 034, time 20:47 UT, "G" - tracking GPS satellite PRN 11 (or GLONASS satellite if "R").

similarity in the profile form, both bottomside and topside, (2) only small differences in $\mathrm{Ne}$ around the F2 peak (less than 10\%), and (3) close values of the F2 peak height (267 vs. $270 \mathrm{~km}$ ). The ionosonde-derived EDP (red curve) appeared to be between RO values. The topside part of the ionosonde-derived EDP (red dots) is reconstructed not from real measurements, but from the model fitting that does not represent real distribution of the topside electron density - thus, we should expect some discrepancies in the topside. Here, we found a very good agreement between collocated RO and ionosonde $\mathrm{Ne}$ measurements in the conditions of local summer, local evening time ( 22 LT), and middle latitudes. 
Figure $2 \mathrm{~b}$ shows the next case comparing GPS and GLONASS RO events that were registered simultaneously by the same COSMIC-2 spacecraft E3. These two RO events occurred near the Ramey ionosonde, Puerto Rico, during daytime at $\sim 14 \mathrm{LT}$ and local winter conditions. The geometry of occultations was slightly different, the GLONASS-based RO trace was much longer and located northward from the ionosonde. We find an apparent difference in the bottomside part of RO EDPs, when the northward GLONASS occultation shows similar $\mathrm{Ne}$ values at the E layer altitude $(\sim 100 \mathrm{~km})$ with a more pronounced E-F valley at higher altitudes. But at the F2 peak layer, both GPS and GLONASS RO EDPs provide very close values of $\mathrm{NmF} 2$ and $\mathrm{hmF} 2$, which agreed well with the reference values given from the collocated ionosonde.

Figure 2c illustrates an opposite example when two COSMIC-2 spacecraft E2 and E5 simultaneously tracked the same GLONASS satellite R15. That colocation event resulted in two relatively short RO traces in the vicinity of the Lualualei ionosonde, Hawaii, USA. Comparison of two RO EDPs shows a very similar shape of both EDPs in the bottomside part but some differences in $\mathrm{Ne}$ near the F2 peak. Here, the ionosonde-based measurements provide $\mathrm{hmF} 2$ of $215 \mathrm{~km}$, while RO-based measurements give us 221 and $216 \mathrm{~km}$. We should highlight here the most important difference between two techniques. Ionosonde-based measurement with a proper scaling provide very accurate $\mathrm{F} 2$ peak density values (foF2/NmF2) for that particular moment of time and location. For the F2 peak height (hmF2), accuracy of ionosonde inversions from virtual to real heights strongly depends on (1) how precisely all $\mathrm{Ne}$ density values were scaled from the whole bottomside from the $\mathrm{E}$ region up to the $\mathrm{F} 2$ peak, and (2) ionogram quality, scaling/auto-scaling errors, and the inversion algorithm performance. Depending on ionogram scaling results, the hmF2 estimates can vary by several dozens of kilometers. On the other hand, the RO-based technique provides unbiased estimates of the F2 peak density height $(\mathrm{hmF} 2)$, whereas the peak density $\mathrm{NmF} 2$ can be affected by Abel inversion errors. For this particular case (Fig. 2c), we note that $\mathrm{NmF} 2$ values derived from two RO profiles are slightly different, whereas hmF2 values are very close to each other and the ionosonde-derived hmF2 estimate.

Figure $2 \mathrm{~d}$ presents another example of two collocated RO events based on GLONASS signal tracking only. Here, two COSMIC-2 spacecraft, E3 and E4, tracked signals from the GLONASS satellite R05. This case corresponded to winter morning conditions over the Athens ionosonde at European midlatitudes. The geometry of both occultations is quite similar. Some difference in the RO event duration (a longer RO projection for E3 satellite) is explained by the fact that E3 satellite was still at a higher orbit of $\sim 730 \mathrm{~km}$ altitude, while the E4 satellite had already descended to a lower, operational orbit of $\sim 540 \mathrm{~km}$ altitude. The orbit altitude difference is also seen on the resulted $\mathrm{Ne}$ EDPs in Figure 2d, right plot. For this RO events occurring at midlatitudes, we find a very good agreement of the derived F2 peak parameters $(\mathrm{NmF} 2$ and $\mathrm{hmF} 2)$ from both $\mathrm{RO}$ events with the reference, ionosonde-derived values.

The presented examples on Figures $2 \mathrm{a}-2 \mathrm{~d}$ illustrate well that utilization of GLONASS signals for RO EDPs retrieval allows one to obtain EDPs with a quality comparable with the traditional GPS-based heritage. Tracking several GNSS system simultaneously allows for a noticeable increase in the number of $\mathrm{RO}$ retrievals and promotes a better observational coverage for operational, climatological, and ionospheric weather applications.

Next, we consider several examples with collocation of more than two RO events.

Figure 2e shows a case when three COSMIC-2 spacecraft (E2, E3, and E4) provided three collocated RO events in the vicinity of the Niue ionosonde at low latitudes of the Pacific Ocean. All three RO EDPs were obtained from tracking the same GPS satellite, PRN G27. The event corresponded to local summer conditions and local evening time (20-21 LT). The geographical projections of the EDPs tangent points were rather short in space and located nearby the Niue ionosonde. The three independent RO EDPs demonstrate an excellent agreement in shape of both the bottomside and topside parts, and the major peak parameters (hmF2 and NmF2). The RO-based F2 peak heights differ by $1-2 \mathrm{~km}$ for the three profiles. The ionosondederived peak height was lower by $15 \mathrm{~km}$ than the RO-based ones. The ionosonde-derived peak density $\mathrm{NmF} 2$ was close to the RO-based results.

Figure $2 \mathrm{f}$ shows three collocated RO events near the Cachoeira Paulista, Brazil, South America, during local morning hours (08-09 LT). Three COSMIC-2 spacecraft E2, E5, and E6 tracked the same GPS satellite G32. The ionosondeand RO-derived EDPs show well-defined E-F1-F2 layers at the bottomside profile with similar values. Two RO events from the spacecraft E2 and E6 (black and green lines overlapping each other on Fig. 2f, left plot) were practically identical in RO geometry and time; the corresponding RO EDPs are nearly identical as well, their bottomside shape of the profile and the F2 peak parameters were the closest to the ionosonde-derived values. The third RO event from the E5 spacecraft (blue line) had the F2 peak point located further southward from the ionosonde. The corresponding RO EDP had a slightly larger $\mathrm{NmF} 2$ but was closer in $\mathrm{hmF} 2$ value to the ionosonde-derived one. Here, the ionosonde provided the hmF2 estimate of $243 \mathrm{~km}$, the RO-derived hmF2 from E5 was $240 \mathrm{~km}$, while 250 and $256 \mathrm{~km}$ were obtained from E2 and E6 satellites, respectively. All these hmF2 results are reasonable with respect to the accuracy and precision of the ionosonde-derived true height hmF2.

Figure $2 \mathrm{~g}$ presents an example of four collocated RO events that occurred near the Darwin ionosonde, Australia, at local summer conditions and local evening time (20-21 LT). Here, four COSMIC-2 spacecraft E1, E2, E3, and E5 tracked simultaneously the same GPS satellite G17. The projections of RO tangent points corresponded to the F2 peak clustered very close to the ionosonde location. As a result, all four independent RObased EDPs appear to be nearly identical. The bottomside part of profile and the F2 peak parameters were remarkably similar to that of the reference, the ionosonde-derived $\mathrm{Ne}$ profile.

Figure $2 \mathrm{~h}$ shows a rarer case with five collocated $\mathrm{RO}$ events. Here, three different COSMIC spacecraft E2, E3, and E5 tracked simultaneously signals from two GPS satellites G07 and G10. These RO events occurred near the Sao Luis ionosonde, Brazil, close to the magnetic equator during local evening hours (18-19 LT). For this case, the geometry of RO tracks was different, and they intersected the equatorial ionization anomaly region in various ways. However, the bottomside part of each RO profiles was in proximity of the ionosonde 

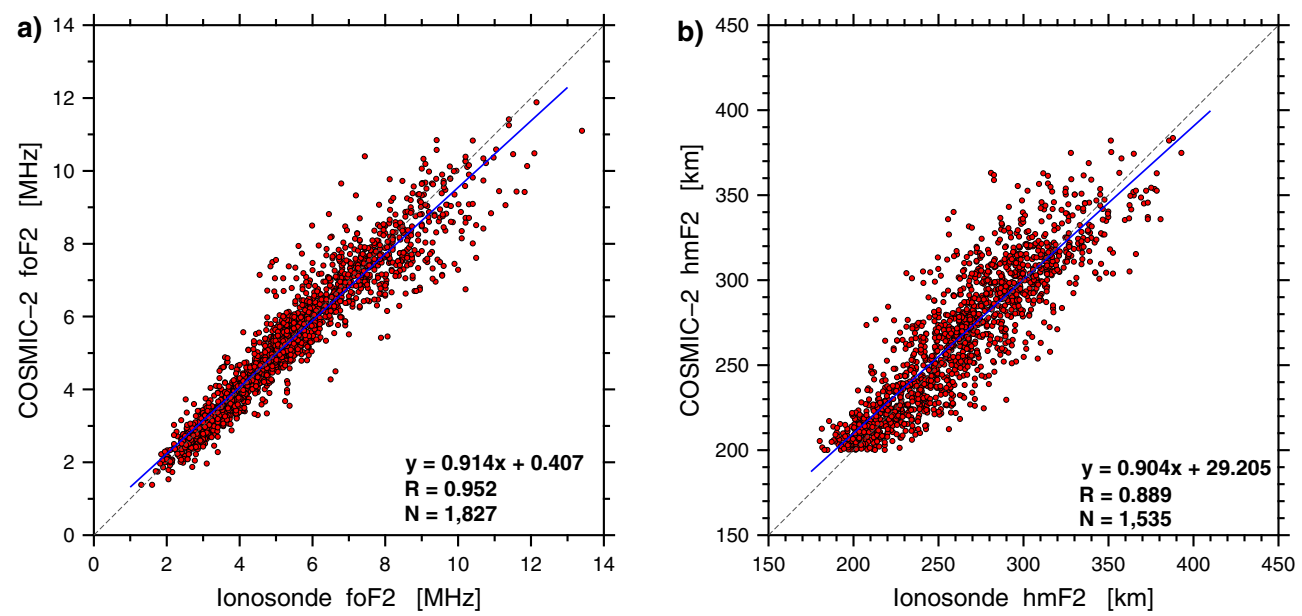

Fig. 3. Scatter plots of the COSMIC-2 RO-based foF2 and hmF2 values against the corresponding ionosonde-derived ones. The solid blue line shows the best fit line (linear regression line).

position. For these specific conditions and location, all five RO-based profiles reveal a similar behavior, consistent values of the F2 peak height (these five RO-based hmF2 values were within a narrow 297-307 km range), and a good agreement with the ionosonde-derived $\mathrm{Ne}$ results.

Thus, the examined representative cases with different RO geometry, multi-satellite and multi-GNSS occultation events provide observational evidence that COSMIC-2 RO-based EDPs derived from GPS and GLONAS links are quite selfconsistent in terms of the ionospheric F2 peak values and $\mathrm{Ne}$ profile shape. Direct comparisons of this COSMIC-2 RO-based ionospheric product against the benchmark/reference ionosonde observations show excellent performance of this new mission for specification of the ionospheric bottomside and the F2 peak regions. At the same time, the multiple collocation $\mathrm{RO}$ events demonstrate a reasonably high precision for the topside ionosphere's measurements, which are in a great demand for improvement of actual empirical and first-principle ionospheric models.

\subsection{Statistical analysis of the COSMIC-2 RO-based F2 peak parameters accuracy}

\subsubsection{Global scale}

For the statistical analysis, we made comparisons in the plasma (critical, foF2) frequencies domain because the reference instrument - ionosonde - provides primary measurements of frequency of radio signal reflected from an ionospheric layer with particular density $\left(\mathrm{Ne}\left[\mathrm{el} / \mathrm{cm}^{3}\right]=1.24 \times 10^{4} \cdot(f[\mathrm{MHz}])^{2}\right)$. The statistical dataset was based on direct collocations between COSMIC-2 and ionosonde-derived EDPs in terms of the ionospheric F2 peak density and height. We compare COSMIC-2 RO-based foF2 and hmF2 values with the closest ionosonde data; the F2 peak location from the reconstructed RO-based profile should be within $\sim 500 \mathrm{~km}\left(5^{\circ}\right)$ from an ionosonde. This dataset covers two months of January-February 2020, a period of low solar activity. Both COSMIC-2 RO EDPs and ionograms were manually checked and quality controlled before including into this dataset. For the analysis, we removed RO EDPs affected by cycle-slips and other unknown irregularities that were not marked bad by CDACC quality control (less than $1 \%$ ), as well as ionograms with spread F, F-layer blanketing by strong Es, and effects of absorption that make inaccessible information about the $\mathrm{F} 2$ peak parameters from the ionosonde measurements. Thus, from 2200 events of COSMIC-2 RO profiles collocation with ionosondes in space and time, $\sim 17 \%$ analyzed ionograms were removed from the analysis mainly due to the equatorial plasma density irregularities presence in the post-sunset time. Some ionograms like from VIPIR-2 ionosondes in Japan were scaled for the critical frequency foF2 only. For all others, true height inversion and $\mathrm{Ne}$ profiles were obtained with the SAO Explorer software.

Figures $3 \mathrm{a}$ and $3 \mathrm{~b}$ present the results of the ionospheric F2 peak comparisons for foF 2 and $\mathrm{hmF} 2$ values as derived from the COSMIC-2 RO-based EDPs against the nearest ionosonde data. The cross-comparisons between two independent measurements of the F2 peak parameters reveal a high degree of correlation of 0.952 and 0.899 for foF 2 and $\mathrm{hmF} 2$, respectively. For both parameters, a slope of the best fit line is found to be $\sim 0.9$, close to 1.0 , showing a strong relationship between two types of measurements. Despite the fact that the matched collocation points correspond mainly to the most variable, equatorial region of the ionosphere, the results show a rather close, symmetrical distribution of the F2 peak parameters as derived from space- and ground-based measurements simultaneously.

\subsubsection{Longitudinal sectors}

The COSMIC-2 RO events occur mainly over the tropical region, covered mostly by oceans and with a very uneven distribution of ground-based instruments, particularly ionosondes (cf. Fig. 1). The next question is to check if the obtained statistical agreement is valid for an entire range of longitudes. We divided our results into three longitudinal sectors: the American, Europe-African, and Asia-Pacific ones within a longitudinal range of $130^{\circ} \mathrm{W}-30^{\circ} \mathrm{W}, 30^{\circ} \mathrm{W}-60^{\circ} \mathrm{E}$, and $90^{\circ} \mathrm{E}-150^{\circ} \mathrm{W}$, respectively. The ionosonde location subdivision into sectors is also presented in Table 1. Figure 4 shows the results of statistical analysis made with a separation into the three longitudinal sectors. First, we can note that a number of matching points in these sectors is quite different. In the American sector 


\section{American sector}

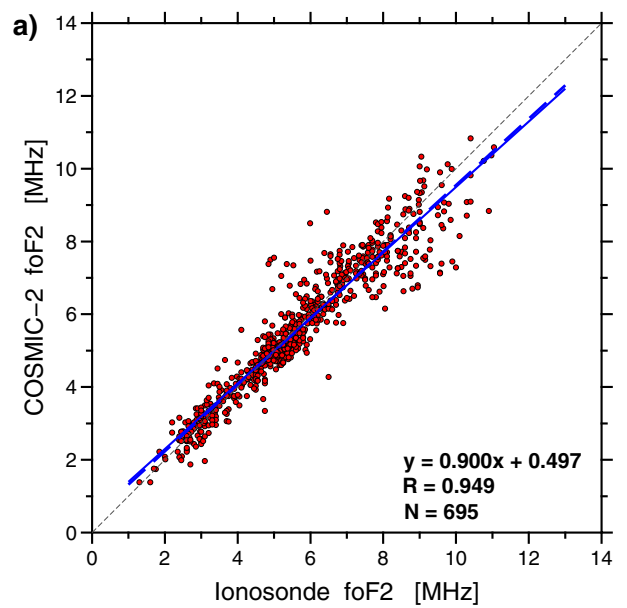

\section{Europe-African sector}

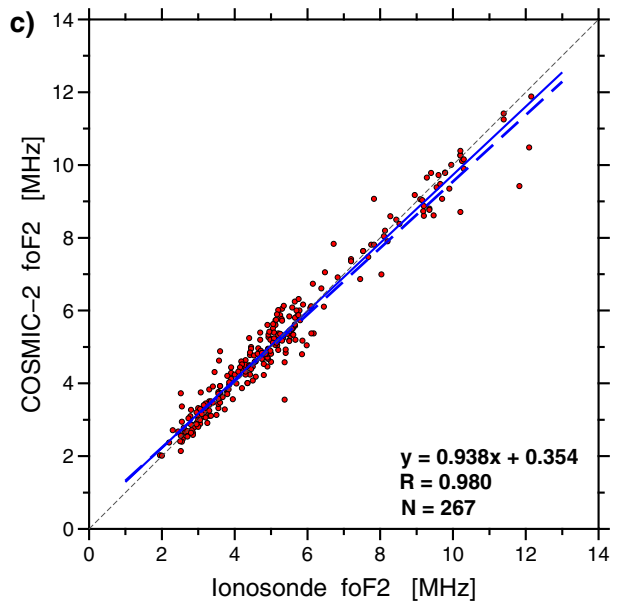

Asia-Pacific sector

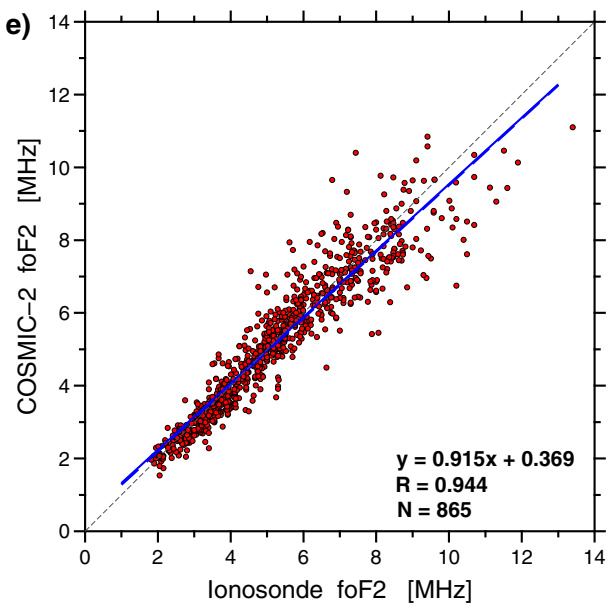

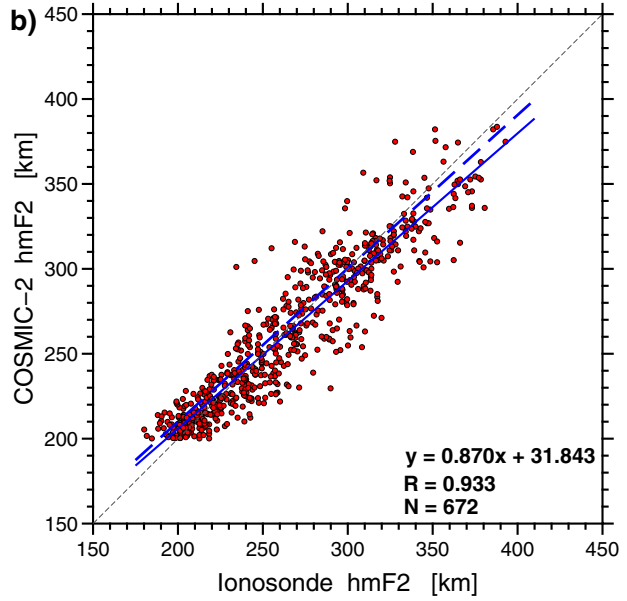
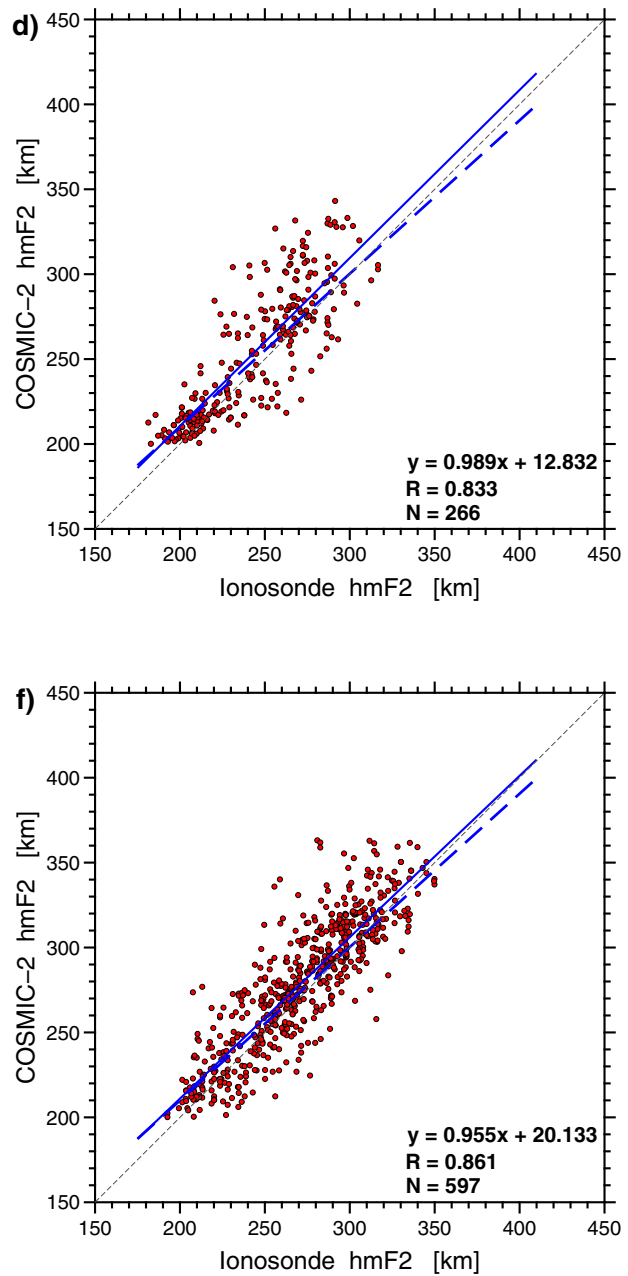

Fig. 4. Scatter plots of the COSMIC-2 RO-based foF 2 and $\mathrm{hmF} 2$ values against the corresponding ionosonde-derived ones with a separation to American, Europe-African, and Asia-Pacific longitudinal sectors. The solid blue lines show the best fit line, while the dashed blue lines show the best fit lines without zone separation (Fig. 3).

(Fig. 1), we have a better and denser ionosonde coverage from middle latitudes to the magnetic equator, whereas the ionosonde locations correspond mainly to midlatitudes in the
Europe-African sector and low-to-middle latitudes in the Asia-Pacific sector. We found a very strong correlation between RO-based and ionosonde-derived measurements of the critical 


\section{All regions}

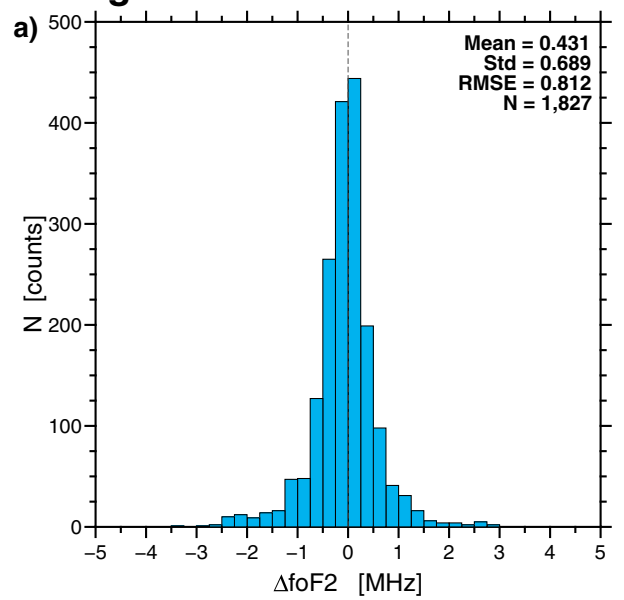

Low latitudes (IMLATI $\left.<30^{\circ}\right)$

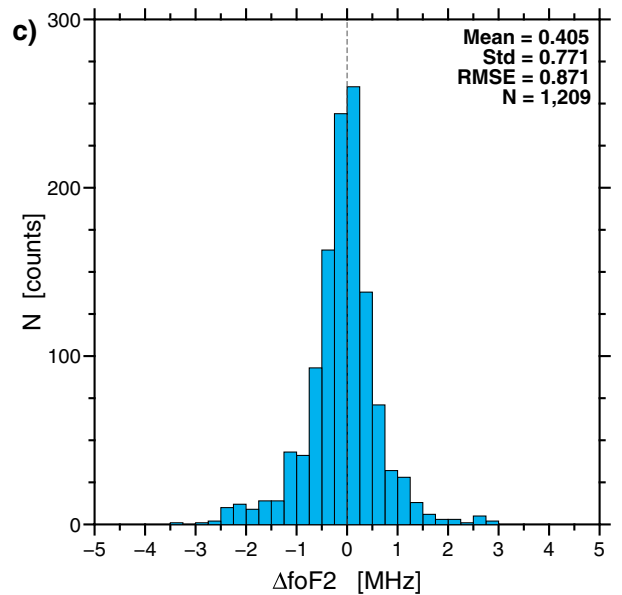

Middle latitudes (IMLATI $\left.>30^{\circ}\right)$

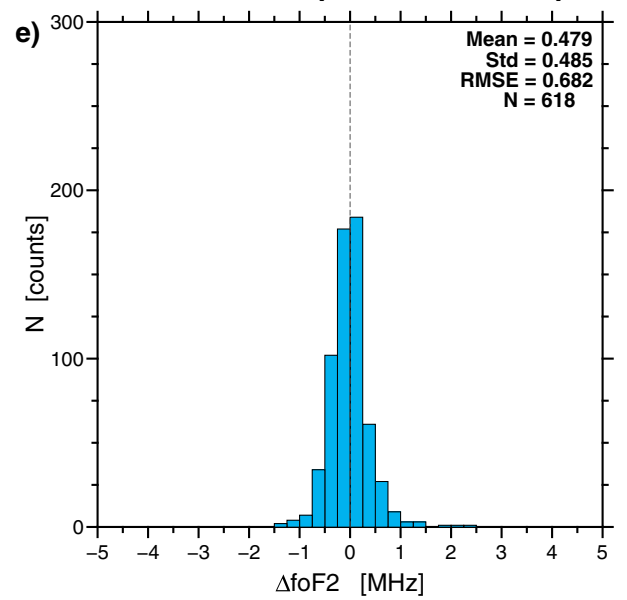

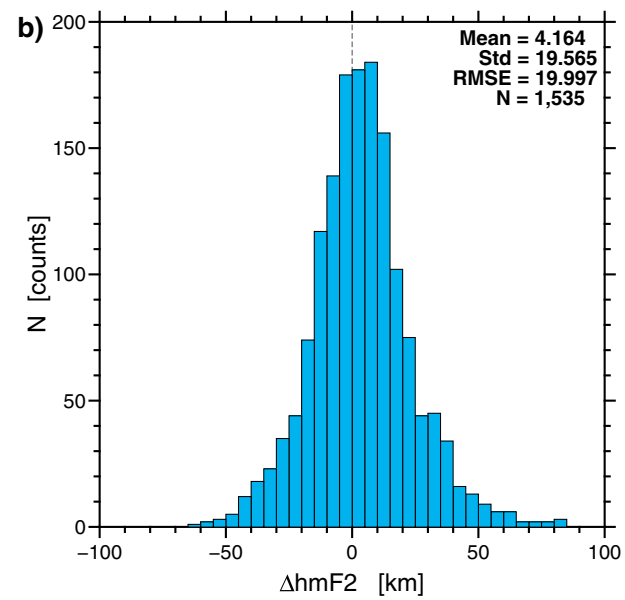
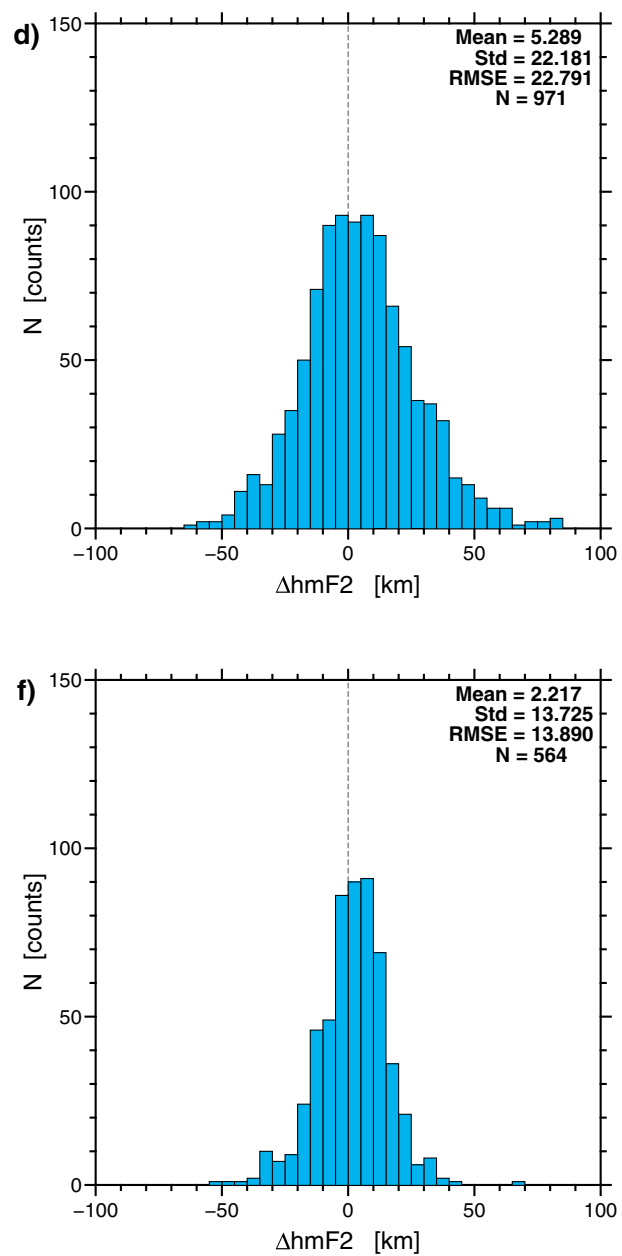

Fig. 5. Histograms of the $\mathrm{F} 2$ peak parameters residuals $\Delta$ foF $2\left(\Delta \mathrm{foF} 2=\right.$ foF $\left.2_{\mathrm{RO}}-\mathrm{foF} 2_{\text {ionosonde }}\right)$ and $\Delta \mathrm{hmF} 2\left(\Delta \mathrm{hmF} 2=\mathrm{hmF} 2_{\mathrm{RO}}-\right.$ $\mathrm{hmF} 2$ ionosonde) between collocated COSMIC-2 and ionosonde measurements for (a-b) all regions and (c-f) with a division into low and middle latitudes. Each plot contains information about the mean, standard deviation, RMS error, and total number of matches.

frequency foF 2 in all three sectors. The very narrow scattering and the highest value of $R=0.98$ are found in the EuropeAfrican sector (Fig. 4c), whereas matches come mainly from collocations with mid-latitude ionosondes in Europe and
Southern Africa. This agreement is consistent with results of COSMIC-1 EPDs validation analysis with European Digisondes (Krankowski et al., 2011). For the American (Fig. 4a) and Asia-Pacific (Fig. 4e) sectors with larger ionospheric variability 
Table 2. Summary of the F2 peak parameters residuals $\Delta$ foF2 and $\Delta \mathrm{hmF} 2$ between collocated COSMIC-2 and ionosonde measurements in absolute $\left(\Delta X=X_{\mathrm{RO}}-X_{\text {ionosonde }}\right)$ and relative $\left(\Delta X(\%)=\left(X_{\mathrm{RO}}-X_{\text {ionosonde }}\right) \times 100 /\left(X_{\text {ionosonde }}\right)\right)$ values. The dataset is subdivided into low/middle latitudes zones and daytime/nighttime conditions. Cells with orange and cyan shading show maximal and minimal values of the residuals mean, respectively.

\begin{tabular}{|c|c|c|c|c|}
\hline & \multicolumn{2}{|c|}{ Absolute values } & \multicolumn{2}{|c|}{ Relative values (\%) } \\
\hline & Mean & SD & Mean & SD \\
\hline \multicolumn{5}{|l|}{ hmF2 } \\
\hline Middle latitudes & $2.217 \mathrm{~km}$ & $13.725 \mathrm{~km}$ & $1.224 \%$ & $5.708 \%$ \\
\hline Low latitudes, day (08-20 LT) & $7.793 \mathrm{~km}$ & $23.913 \mathrm{~km}$ & $3.238 \%$ & $8.775 \%$ \\
\hline Low latitudes, night (20-08 LT) & $1.944 \mathrm{~km}$ & $19.170 \mathrm{~km}$ & $0.807 \%$ & $7.081 \%$ \\
\hline \multicolumn{5}{|l|}{ foF2 } \\
\hline Low latitudes & $0.405 \mathrm{MHz}$ & $0.771 \mathrm{MHz}$ & $11.355 \%$ & $18.205 \%$ \\
\hline Middle latitudes & $0.479 \mathrm{MHz}$ & $0.485 \mathrm{MHz}$ & $14.049 \%$ & $14.789 \%$ \\
\hline Low latitudes, day (08-20 LT) & $0.346 \mathrm{MHz}$ & $0.897 \mathrm{MHz}$ & $7.274 \%$ & $14.874 \%$ \\
\hline Low latitudes, night (20-08 LT) & $0.483 \mathrm{MHz}$ & $0.565 \mathrm{MHz}$ & $16.548 \%$ & $20.565 \%$ \\
\hline
\end{tabular}

and plasma density gradients, we found a greater foF 2 data scattering, but the correlation remains very high $(R=0.94)$. The slope of the best fit line was quite similar at all longitudes (cf. dashed blue lines with a solid blue line).

Data comparison for the F2 peak heights (Fig. 4, right column) reveal a larger scattering than that of foF2 values. The range of the data scatter looks quite similar in the American sector with good coverage of the equatorial ionosphere and in the Europe-American sector where ionosondes provide mainly information about the calm, homogeneous mid-latitude ionosphere. This can be explained by some limitations of the true height conversion technique applied in the ionogram processing that can provide difference up to $10-30 \mathrm{~km}$ in the true $\mathrm{hmF} 2$ determination. So, for all regions and latitudes, we should expect larger scatter for the $\mathrm{hmF} 2$ parameter, even with using the manual scaling of the ionograms. Despite the fact that many of collocation points come from the equatorial and low-latitude zone, the correlation between independent measurements of $\mathrm{hmF} 2$ was found to be higher in the American and Asia-Pacific sectors, 0.93 and 0.86 , respectively. It can be also related that these two sectors have a larger number of matching points to build up the statistical results.

These results indicate a very good agreement between the collocated COSMIC-2 RO-based and the reference, ionosonde observations and demonstrate that the retrieved $\mathrm{F} 2$ peak parameters foF 2 and $\mathrm{hmF} 2$ are reliable within the operational zone of the new COSMIC-2 constellation.

\subsubsection{Latitudinal zones}

Though the COSMIC-2 mission has a low inclination orbit $\left(24^{\circ}\right)$ and the satellites overfly the equatorial and low-latitudinal ionosphere, specific advantages of the RO technique allow to perform RO soundings faraway from a LEO position. Figure $1 \mathrm{~b}$ shows that numerous RO events occur even at midlatitudes up to $\sim 40^{\circ}$ GLAT. Thus, we can analyze statistical distribution of the ionospheric F2 peak ionosphere parameters residuals accounting different latitudinal zones.
Figures $5 \mathrm{a}$ and $5 \mathrm{~b}$ present the resulting histograms for the ionospheric F2 peak parameters residuals between collocated COSMIC-2 RO and ionosonde measurements made for the entire dataset. Using the standard statistical analysis procedures, we calculate the RO-ionosonde measurement residuals and the major characteristics of these residuals: mean, standard deviation (SD), and root mean square error (RMSE). The residuals for the $\mathrm{F} 2$ peak critical frequency $\left(\Delta \mathrm{foF} 2=\right.$ foF $2_{\mathrm{RO}}-$ foF $\left.2_{\text {ionosonde }}\right)$ and the $\mathrm{F} 2$ peak height $\left(\Delta \mathrm{hmF} 2=\mathrm{hmF} 2_{\mathrm{RO}}-\right.$ $\mathrm{hmF} 2_{\text {ionosonde }}$ ) are expressed in $\mathrm{MHz}$ and $\mathrm{km}$, respectively. Figure $5 \mathrm{a}$ shows a rather narrow distribution of the $\Delta \mathrm{foF} 2$ residuals, characterized by an absolute mean value of $0.43 \mathrm{MHz}$ with SD of $0.69 \mathrm{MHz}$, meaning that COSMIC-2 tends to slightly overestimate the ionosonde-derived peak density. For the F2 peak height, a wider distribution of the $\Delta \mathrm{hmF} 2$ residuals was found with a small positive bias - the mean value of $4.16 \mathrm{~km}$ and SD of $19.57 \mathrm{~km}$ (Fig. 5b). Taking into account the accuracy limitation of the ionosonde-derived true height inversion, the obtained results with the hmF2 accuracy and precision assessment $(4.16 \pm 19.57 \mathrm{~km})$ prove a high quality of the COSMIC-2 RO-based EDP products and confirm the high degree of consistency of these observations with the reference, ionosonde measurements, actually for all longitudinal sectors and a latitudinal range $40^{\circ} \mathrm{S}-40^{\circ} \mathrm{N}$ GLAT.

Further, we subdivided the entire dataset into the low latitude region to be within $30^{\circ} \mathrm{S}-30^{\circ} \mathrm{N}$ magnetic latitudes (MLAT) and the middle latitudes region (poleward from $30^{\circ} \mathrm{MLAT}$ ). For the F2 peak height parameter, we found a clear difference between these two regions. At middle latitudes (Fig. 5f), the hmF2 accuracy assessment between RO and reference measurement techniques was found to be $(2.22 \pm$ $13.73 \mathrm{~km}$ ); this value is very close to the accuracy results of $(2.80 \pm 11.46 \mathrm{~km})$ reported for validation of COSMIC-1 RO EDPs with a chain of ionosondes at European midlatitudes (Krankowski et al., 2011). At equatorial and low latitudes (Fig. 5d), the statistical characteristics for the hmF2 residuals are $1.5-2.0$ times larger than those of the middle latitude region - here, the accuracy estimate is $(5.29 \pm 22.18 \mathrm{~km})$, 
and the $\Delta \mathrm{hmF} 2$ residuals form a wider histogram shape. These regional differences can be explained by two reasons. First, there is a larger ionospheric variability at low latitudes. Second, in the conditions of quiet mid-latitude ionosphere ionograms have typically a better quality and the ionogram inversion algorithm has a good performance.

For the F2 peak density, the $\Delta$ foF 2 residuals has a narrow distribution at middle latitudes (Fig. 5e). Here, a mean difference value was $0.48 \mathrm{MHz}$ with a standard deviation of $0.49 \mathrm{MHz}$ and RMSE of $0.69 \mathrm{MHz}$. At low latitudes (Fig. 5c), the $\Delta$ foF2 residuals have a mean value of $0.41 \mathrm{MHz}$ and larger SD and RMSE values of $0.77 \mathrm{MHz}$ and $0.87 \mathrm{MHz}$, respectively. These values are in a good agreement with results of the COSMIC-1 RO foF2 assessment made by McNamara \& Thompson (2015) using foF2 data manually scaled from the Australian ionosondes network and 1871 collocation points during 9 months of 2007/2008, they report SD and RMSE of $\sim 0.5 \mathrm{MHz}$ at midlatitude stations of the Australian region and increasing up to $\sim 1.0-1.6 \mathrm{MHz}$ at equatorial/low latitudes.

Table 2 summarizes the retrieval characteristics of the F2 peak parameters assessment in the form of absolute and percentage values for mean and SD of the $\Delta \mathrm{foF} 2$ and $\Delta \mathrm{hmF} 2$ residuals. We present these values for the low and mid latitudes regions entirely, and with a subdivision into local daytime/nighttime conditions. The cells with color shading indicate minimal/ maximal values of the mean discrepancies. For $\Delta \mathrm{hmF} 2$ values, the minimal mean values $(0.5 \mathrm{~km})$ were found at midlatitudes during local night hours, while maximal mean $(7.8 \mathrm{~km})$ was registered at low latitudes during daytime. In general, SD and RMSE values for $\Delta \mathrm{hmF} 2$ were found to be $\sim 20-25 \mathrm{~km}$ at low latitudes and $\sim 13-15 \mathrm{~km}$ at middle latitudes; that range corresponds to deviation of $6-9 \%$ from the reference, ionosonde observations. For $\Delta$ foF 2 values, the mean of absolute difference was found below or equal to $0.5 \mathrm{MHz}$ for all specified sectors and LT conditions. The minimal mean value of $\sim 0.35 \mathrm{MHz}$ $(\sim 7 \%)$ was observed at low latitudes during daytime, in the conditions of the most developed F2 peak layer. The SD and RMSE values for $\Delta$ foF2 were $\sim 0.6-0.9 \mathrm{MHz}$ at low latitudes and $\sim 0.4-0.5 \mathrm{MHz}$ at middle latitudes. Similar effect was found for previous RO missions, in particular, Jakowski et al. (2005) reported the systematic positive bias of $\sim 0.4-0.5 \mathrm{MHz}$ with RMS dispersion of $1 \mathrm{MHz}$ for CHAMP RO EDPs comparisons with European midlatitude ionosondes. Garcia-Fernandez et al. (2005) reported positive bias in absolute error in foF2 measurements as $\sim 0.7-0.8 \mathrm{MHz}$ for GPS/MET, $\sim 1.0-1.3 \mathrm{MHz}$ for $\mathrm{SAC} / \mathrm{C}$, and $\sim 1.1-1.5 \mathrm{MHz}$ for CHAMP using collocation distance of up to $2000 \mathrm{~km}$ between $\mathrm{RO}$ and ionosonde locations and $1 \mathrm{hr}$ of time window. It is important to note that larger errors in the peak density determination by the COSMIC-2 RO technique at low latitudes can be related with the Abel inversion errors from spherical symmetry assumption that is not always valid at equatorial latitudes. Yue et al. (2010) simulated errors introduced by Abel inversion retrieval technique at low latitudes and reported SD of the relative retrieval error of $\sim 5-15 \%$ for $\mathrm{NmF} 2$. Thus, a noticeable part of the RO-ionosonde discrepancies in foF2 relates to errors with classic Abel inversion technique. As reported by Yue et al. (2010), in COSMIC-1 observation these overestimates features were pronounced near the equator and in the north and south of the EIA crests. Our results show a similar positive bias in area of the COSMIC-2 mission operation within $\pm 30^{\circ}$ MLAT. So, these results are consistent with the preceding RO missions when the standard Abel inversion is used for ionospheric EDP retrieval. Generally, the retrieved $\mathrm{NmF} 2$ and $\mathrm{hmF} 2$ are in good agreement with the true values, taking into account the current Abel retrieval method used for the COSMIC-2 electron density profiles product.

\section{Summary}

Analysis of the early results from the COSMIC-2 mission against the reference ground-based data for both the low and midlatitude regions demonstrates that COSMIC-2 RO profiles are in a good agreement with reference ionosonde observations both in the F2 layer peak electron density specified by the foF2 value and the peak height hmF2.

Validation of measurements from any new mission is a challenging task mainly performed by experts, it is time-consuming work that requires a detailed analysis and statistical generalization of a large amount of data. In this study, we avoid errors related to auto-scaling processing by manual checking and editing of the ionosonde data, including cases of doubtful ionograms scaling under F-spread conditions. At this point, these results provide more careful and precise estimates of the F2 peak parameters assessments compared to those made on the basis of auto-scaled ionograms only. Our results also confirmed that RO EDPs derived from traditional GPS signals tracking and from newly implemented GLONASS tracking are in a good agreement in terms of the ionospheric F2 peak values and $\mathrm{Ne}$ profile shape.

Great performance of COSMIC-2 ionospheric retrievals has been evaluated with statistical analysis for the early results COSMIC-2 dataset of 2200 electron density profiles selected as collocation events with 29 globally distributed ground-based ionosondes. The new mission is shown to provide accurate profiles of the ionospheric electron density.

The quantitative residuals values for peak parameter are:

(a) The minimal mean values for $\Delta \mathrm{hmF} 2$ is $0.5 \mathrm{~km}$ at midlatitudes during local night hours. The maximal mean for $\Delta \mathrm{hmF} 2$ is $7.8 \mathrm{~km}$ at low latitudes during daytime.

(b) The SD and RMSE values for $\Delta \mathrm{hmF} 2$ are $\sim 20-25 \mathrm{~km}$ at low latitudes and $\sim 13-15 \mathrm{~km}$ at middle latitudes

(c) For $\Delta$ foF 2 , the general percentage deviations are $6-9 \%$ from the reference ionosonde values. The mean of absolute difference in $\Delta$ foF2 is below to 0.5 .

(d) The minimal mean $\Delta$ foF2 value is $\sim 0.35 \mathrm{MHz}(\sim 7 \%)$ corresponded to low latitudes during daytime, in the conditions of the most developed F2 peak layer.

(e) SD and RMSE values for $\Delta$ foF2 were $\sim 0.6-0.9 \mathrm{MHz}$ at low and $\sim 0.4-0.5 \mathrm{MHz}$ at middle latitudes.

Finally, we should conclude that the COSMIC-2 RO derived ionospheric data appear to be consistent with benchmark measurements in this early validation study and that COSMIC-2 has excellent performance for specification of ionospheric electron density. We expect that COSMIC-2 ionospheric products delivered to scientific community when the satellites reach their operational orbit configuration will make significant contributions to ionospheric studies, including 
improvement in understanding of the equatorial ionosphere climatology and dynamics.

Acknowledgements. COSMIC-2 provisional space weather data are provided by COSMIC Data Analysis and Archive Center (https://doi.org/10.5065/t353-c093). Raw ionograms from the DIDBase Digisonde network are available through GIRO (http://giro.uml.edu/; http://spase.info/VWO/DisplayData/ GIRO/GRM.PT15M) and were scaled using the SAO Explorer tool. This paper uses ionospheric data from the USAF NEXION Digisonde network, the NEXION Program Manager is Mark Leahy. Data from the Brazilian Ionosonde network is made available through the EMBRACE program from the National Institute for Space Research (INPE). Data from the South African Ionosonde network is made available through the South African National Space Agency (SANSA), who are acknowledged for facilitating and coordinating the continued availability of data. Data from ionosonde stations in Japan are provided by NICT, Japan (http://wdc.nict.go.jp/ionog/ js_viewer/js_01.html). We are grateful to the Australian Bureau of Meteorology, Space Weather Services for provision data from Australian ionosonde stations (https://www.sws. bom.gov.au/HF_Systems/1/3). This material is based upon work supported by the National Center for Atmospheric Research, which is a major facility sponsored by the National Science Foundation under Cooperative Agreement No. 1852977. The research is supported by the National Science Foundation CAS AGS-1033112 grant and by Air Force Contract FA8803-19-C-0004. This paper was prepared under award AB-133E-16-CN-0070 from NOAA, U.S. Department of Commerce. The editor thanks Ljiljana Cander and an anonymous reviewer for their assistance in evaluating this paper.

\section{References}

Altadill D, Segarra A, Blanch E, Juan JM, Paznukhov VV, Buresova D, Galkin I, Reinisch BW, Belehaki A. 2020. A method for realtime identification and tracking of traveling ionospheric disturbances using ionosonde data: First results. J Space Weather Space Clim 10: 2. https://doi.org/10.1051/swsc/2019042.

Arras C, Wickert J, Beyerle G, Heise S, Schmidt T, Jacobi C. 2008. A global climatology of ionospheric irregularities derived from GPS radio occultation. Geophys Res Lett 35(14): 2-5. https://doi. org/10.1029/2008GL034158.

Belehaki A, Jakowski N, Reinisch BW. 2003. Comparison of ionospheric ionization measurements over Athens using ground ionosonde and GPS-derived TEC values. Radio Sci 38(6): 1-11. https://doi.org/10.1029/2003rs002868.

Chen CF, Reinisch BW, Scali JL, Huang X, Gamache RR, Buonsanto MJ, Ward BD. 1994. The accuracy of ionogramderived N(h) profiles. Adv Space Res 14(12): 43-46. https://doi. org/10.1016/0273-1177(94)90236-4.

Cherniak IV, Zakharenkova IE, Krankowski A, Shagimuratov II. 2012. Plasmaspheric electron content derived from GPS TEC and FORMOSAT-3/COSMIC measurements: Solar minimum condition. Adv Space Res 50(4): 427-440. https://doi.org/10.1016/j. asr.2012.04.002.

Cherniak IV, Zakharenkova IE. 2014. Validation of FORMOSAT-3/ COSMIC radio occultation electron density profiles by incoherent scatter radar data. Adv Space Res 53(9): 1304-1312. https://doi. org/10.1016/j.asr.2014.02.010.

Cherniak I, Zakharenkova I. 2019. Evaluation of the IRI-2016 and NeQuick electron content specification by COSMIC GPS radio occultation, ground-based GPS and Jason-2 joint altimeter/GPS observations. Adv Space Res 63(6): 1845-1859. https://doi.org/ 10.1016/j.asr.2018.10.036.

Dandenault PB, Dao E, Kaeppler SR, Miller ES. 2020. An estimation of human-error contributions to historical ionospheric data. Earth Space Sci 7: e2020EA001123. https://doi.org/10.1029/2020EA001123.

DPS4D Specification. 2020. Digisonde-4D system manual, version 1.2.6. https://digisonde.com/pdf/Digisonde4DManual_LDI-web12-6.pdf. As accessed on December 2020.

Dymond KF, Coker C, Metzler C, McDonald SE. 2017. Evaluation of the performance of ionospheric models at solar maximum using COSMIC slant TEC measurements. Radio Sci 52(3): 378-388. https://doi.org/10.1002/2015RS005908.

Garcia-Fernandez M, Hernandez-Pajares M, Juan JM, Sanz J. 2005. Performance of the improved Abel transform to estimate electron density profiles from GPS occultation data. GPS Solut 9(2): 105-110. https://doi.org/10.1007/s10291-005-0139-5.

Hajj GA, Romans LJ. 1998. Ionospheric electron density profiles obtained with the Global Positioning System: Results from the GPS/MET experiment. Radio Sci 33(1): 175-190. https://doi.org/ 10.1029/97RS03183.

Habarulema JB, Katamzi ZT, Yizengaw E. 2014. A simultaneous study of ionospheric parameters derived from FORMOSAT-3/ COSMIC, GRACE, and CHAMP missions over middle, low, and equatorial latitudes: Comparison with ionosonde data. J Geophys Res: Space Phys 119(9): 7732-7744. https://doi.org/10.1002/ 2014JA020192.

He M, Liu L, Wan W, Ning B, Zhao B, Wen J, Yue XA, Le H. 2009. A study of the Weddell Sea Anomaly observed by FORMOSAT3/COSMIC. J Geophys Res: Space Phys 114(12): A12309. https://doi.org/10.1029/2009JA014175.

Jakowski N, Wehrenpfennig A, Heise S, Reigber C, Lühr H, Grunwaldt L, Meehan TK. 2002. GPS radio occultation measurements of the ionosphere from CHAMP: Early results. Geophys Res Lett 29(10): 1457. https://doi.org/10.1029/2001gl014364.

Jakowski N, Tsybulya K, Mielich J, Belehaki A, Altadill D, JeanClaude Jodogne J-C, Zolesi B. 2005. Validation of GPS ionospheric radio occultation results onboard CHAMP by vertical sounding observations in Europe. In: Earth observation with CHAMP, Reigber C, Lühr H, Schwintzer P, Wickert J (Eds.), Springer, Berlin, Heidelberg. https://doi.org/10.1007/3-54026800-6_70.

Kashcheyev A, Nava B. 2019. Validation of NeQuick 2 model topside ionosphere and plasmasphere electron content using COSMIC POD TEC. J Geophys Res: Space Phys 124: 95259536. https://doi.org/10.1029/2019JA026971.

Kelley MC, Wong VK, Aponte N, Coker C, Mannucci AJ, Komjathy A. 2009. Comparison of COSMIC occultation-based electron density profiles and TIP observations with Arecibo incoherent scatter radar data. Radio Sci 44: RS4011. https://doi.org/10.1029/ 2008 rs004087.

Klimenko MV, Klimenko VV, Zakharenkova IE, Cherniak IV. 2015. The global morphology of the plasmaspheric electron content during Northern winter 2009 based on GPS/COSMIC observation and GSM TIP model results. Adv Space Res 55(8): 2077-2085. https://doi.org/10.1016/j.asr.2014.06.027.

Klobuchar JA, Kunches JM. 2000. Eye on the ionosphere: The spatial variability of ionospheric range delay. GPS Solut 3(3): 7074. https://doi.org/10.1007/PL00012808. 
Krankowski A, Zakharenkova I, Krypiak-Gregorczyk A, Shagimuratov II, Wielgosz P. 2011. Ionospheric electron density observed by FORMOSAT-3/COSMIC over the European region and validated by ionosonde data. J Geodesy 85(12): 949-964. https://doi.org/10.1007/s00190-011-0481-z.

Komjathy A, Wilson B, Pi X, Akopian V, Dumett M, Iijima B, Verkhoglyadova O, Mannucci AJ. 2010. JPL/USC GAIM: On the impact of using COSMIC and ground-based GPS measurements to estimate ionospheric parameters. J Geophys Res: Space Phys 115 (2): A02307. https://doi.org/10.1029/2009JA014420.

Lee IT, Wang W, Liu JY, Chen CY, Lin CH. 2011. The ionospheric midlatitude trough observed by FORMOSAT-3/COSMIC during solar minimum. J Geophys Res: Space Phys 116(6): 1-11. https://doi.org/10.1029/2010JA015544.

Lei J, Syndergaard S, Burns AG, Solomon SC, Wang W, et al. 2007. Comparison of COSMIC ionospheric measurements with groundbased observations and model predictions: Preliminary results. $J$ Geophys Res: Space Phys 112(7): 1-10. https://doi.org/10.1029/ 2006JA012240.

McNamara LF, Thompson DC. 2015. Validation of COSMIC values of foF2 and M(3000)F2 using ground-based ionosondes. Adv Space Res 55(1): 163-169. https://doi.org/10.1016/j.asr.2014.07.015.

Pedatella NM, Larson KM. 2010. Routine determination of the plasmapause based on COSMIC GPS total electron content observations of the midlatitude trough. J Geophys Res: Space Phys 115(9). https://doi.org/10.1029/2010JA015265.

Pedatella NM, Forbes JM, Maute A, Richmond AD, Fang T, Larson KM. 2011. Longitudinal variations in the $F$ region ionosphere and the topside ionosphere-plasmasphere : Observations and model simulations. J Geophys Res 116: A12309. https://doi.org/10.1029/ 2011JA016600.

Pedatella NM, Yue X, Schreiner WS. 2015. An improved inversion for FORMOSAT-3/COSMIC ionosphere electron density profiles. J Geophys Res: Space Phys 120: 8942-8953. https://doi.org/ 10.1002/2015JA021704.

Piggott W.R., Rawer K. 1978. URSI handbook of ionogram interpretation and reduction. World data. Center A, Report UAG-23 A.

Rush CM, Edwards WR. 1976. An automated mapping technique for representing the hourly behavior of the ionosphere. Radio Sci 11 (11): 931-937. https://doi.org/10.1029/RS011i011p00931.

Reinisch BW, Huang X. 2001. Deducing topside profiles and total electron content from bottomside ionograms. Adv Space Res 27(1): 23-30. https://doi.org/10.1016/S0273-1177(00)00136-8.

Reinisch BW, Galkin IA, Khmyrov GM, Kozlov AV, Bibl K, et al. 2009. New Digisonde for research and monitoring applications. Radio Sci 44: RS0A24. https://doi.org/10.1029/2008rs004115.
Reinisch BW, Galkin IA. 2011. Global ionospheric radio observatory (GIRO). Earth Planets Space 63: 377-381. https://doi.org/ 10.5047/eps.2011.03.001.

Reinisch B, Galkin I, Belehaki A, Paznukhov V, Huang X, et al. 2018. Pilot ionosonde network for identification of traveling ionospheric disturbances. Radio Sci 53(3): 365-378. https://doi. org/10.1002/2017RS006263.

Sadighi S, Jayachandran PT, Jakowski N, MacDougall JW. 2009. Comparison of the CHAMP radio occultation data with the Canadian advanced digital ionosonde in the Polar Regions. $A d v$ Space Res 44(11): 1304-1308. https://doi.org/10.1016/j. asr.2009.07.016.

Schreiner WS, Sokolovskiy SV, Rocken C, Hunt DC. 1999. Analysis and validation of GPS/MET radio occultation data in the ionosphere. Radio Sci 34(4): 949-966. https://doi.org/10.1029/ 1999RS900034.

Schreiner WS, Weiss JP, Anthes RA, Braun J, Chu V, et al. 2020. COSMIC-2 radio occultation constellation: First results. Geophys Res Lett 47: e2019GL086841. https://doi.org/10.1029/ 2019GL086841.

Syndergaard S, Schreiner WS, Rocken C, Hunt DC, Dymond KF. 2006. Preparing for COSMIC: Inversion and analysis of ionospheric data products. In: Atmosphere and climate: Studies by occultation methods, Foelsche U, Kirchengast G, Steiner AK (Eds.), Springer, New York, pp. 137-146.

Tien JY, Okihiro BB, Esterhuizen SX, Franklin GW, Meehan TK, Munson TN, Robison DE, Turbiner D, Young LE. 2012. Next generation scalable spaceborne GNSS science receiver. In: Proceedings of the 2012 International Technical Meeting of The Institute of Navigation, Newport Beach, CA, January 2012, pp. 882-914.

Tsai LC, Tsai WH, Schreiner WS, Berkey FT, Liu JY. 2001. Comparisons of GPS/MET retrieved ionospheric electron density and ground based ionosonde data. Earth Planets Space 53: 193 205.

Yue X, Schreiner WS, Lei J, Sokolovskiy SV, Rocken C, Hunt DC, Kuo YH. 2010. Error analysis of Abel retrieved electron density profiles from radio occultation measurements. Ann Geophys 28(1): 217-222. https://doi.org/10.5194/angeo-28-217-2010.

Yue X, Schreiner WS, Rocken C, Kuo YH. 2013. Validate the IRI2007 model by the COSMIC slant TEC data during the extremely solar minimum of 2008. Adv Space Res 51(4): 647-653. https://doi.org/10.1016/j.asr.2011.08.011.

Zakharenkova I, Cherniak I, Shagimuratov I. 2017. Observations of the Weddell Sea Anomaly in the ground-based and space-borne TEC measurements. J Atmos Sol-Terr Phys 161: 105-117. https://doi.org/10.1016/j.jastp.2017.06.014.

Cite this article as: Cherniak I, Zakharenkova I, Braun J, Wu Q, Pedatella N, et al. 2021. Accuracy assessment of the quiet-time ionospheric F2 peak parameters as derived from COSMIC-2 multi-GNSS radio occultation measurements. J. Space Weather Space Clim. 11, 18. https://doi.org/10.1051/swsc/2020080. 